\title{
Varicocelectomy to Treat Pain, and Predictors of Success: A Prospective Study
}

\author{
Mohamed E. Abd Ellatif Waleed Asker Ashraf Abbas Ahamed Negm \\ Mohammed Al-Katary Haitham El-Kaffas Ahmed Moatamed
}

General Surgical Department, Faculty of Medicine, Mansoura University, Mansoura, Egypt

\section{Key Words}

Varicocele $\cdot$ Pain • Varicocelectomy • Outcome

\begin{abstract}
Objective: We attempted to examine the success rate of varicocele ligation when performed for the treatment of pain and to evaluate all the predictor factors that may affect the resolution of pain. Patients and Methods: From January 2008 to January 2011, a total 152 patients presented with painful varicocele to our out-patient clinic. While waiting for surgery, 7 patients (4.6\%) resolved their pain with conservative management and 145 patients underwent varicocelectomy due to failure. The first follow-up visit was after 1 week to check the wounds and 130 patients attended the second visit after 3 months. Follow-up evaluation included physical examination, questioning of pain severity (compared with preoperative pain severity), development of any postoperative complications, and color Doppler to study recurrence reflux. Results: During the study period, 145/397 (36.5\%) patients underwent varicocelectomy for pain. Of the 145 men operated on for pain 130 (89.6\%) were available for follow-up. A subinguinal approach was used in 93 patients (71.5\%) and high ligation in $37(28.5 \%)$. Of the 130 patients contacted after surgery, 109 (83.8\%) reported complete resolution of pain, 7 (5.4\%) had partial resolution of pain and 14 did not show benefit from surgery. There was no association between varicocele grade, quality of pain, type of varicocele ligation, or recurrence and pain resolution after surgery, only the duration of pain seems to be a factor that
\end{abstract}

\section{KARGER}

Fax +41613061234

E-Mail karger@karger.ch

www.karger.com
(C) 2012 S. Karger AG, Basel

1015-9770/12/0061-0033\$26.00/0

Accessible online at

www.karger.com/cur is considerably associated with pain resolution. Conclusion: Varicocelectomy is a successful option for treatment of painful varicocele in selected patients. The duration of pain may predict outcomes in these patients.

Copyright $\odot 2012$ S. Karger AG, Basel

\section{Introduction}

A clinical varicocele is observed in $10-20 \%$ of the general population, in $35-40 \%$ of men with primary infertility and in up to $80 \%$ of men with secondary infertility [1]. It is the cause of pain in $2-14 \%$ of men suffering from chronic scrotal pain [2,3]. Varicocelectomy is indicated in the case of infertility, when the testicular volume is decreased, such as in adolescents, or when associated with persistent pain [4].

The pain of a varicocele can vary from dull discomfort to sharp pain, which may increase after sitting, standing, or physical exertion. Most patients describe the pain as being the worst in a standing position or as the day progresses, and it may be relieved by lying down. Patients with varicocele who consult for pain are always given conservative treatment which is generally followed by surgical ligation [3].

There are different ligation techniques with minimal complication rates $[3,5]$ and there have been many studies of the effectiveness of surgical treatment in patients 
Table 1. Patients characteristics

\begin{tabular}{lc}
\hline Variable & \\
\hline Patients, $\mathrm{n}$ & 130 \\
Age, years & 25.7 (range 19-39) \\
Laterality & \\
$\quad$ Left side & $118(90.8 \%)$ \\
$\quad$ Bilateral & $12(9.2 \%)$ \\
Grade & \\
$\quad$ III & $79(60.8)$ \\
II & $48(36.9 \%)$ \\
I & $3(2.3 \%)$ \\
Preoperative duration of pain, months & $17.8($ range $1-37)$ \\
Pain quality & \\
$\quad$ Dull & $86(66 \%)$ \\
$\quad$ Throbbing ache & $44(34 \%)$ \\
Subinguinal approach & $93(71.5 \%)$ \\
High approach & $37(28.5 \%)$ \\
Complications: & \\
$\quad$ Intraoperative & 0 \\
Postoperaive & $8(6 \%)$ \\
Good response & $109(83.8 \%)$ \\
Partial resolution & $7(5.4 \%)$ \\
Failure & $14(10.8 \%)$ \\
Testicular size, ml & \\
Preoperative & $16 \pm 3.7$ \\
Postoperative & $17.3 \pm 4.7$ \\
Follow-up period, months & $10.9($ range 5-36) \\
\hline
\end{tabular}

treated for infertility, but only a few have reported the results of varicocelectomy performed for pain relief [6-8]. This study attempted to examine the success rate of varicocele ligation when performed for the treatment of pain and to evaluate all the predictor factors that may affect the resolution of pain.

\section{Materials and Methods}

This prospective study included 152 patients with painful varicocele who presented to our ward (Dept. of Surgery, Mansoura University Hospital, Mansoura, Egypt) between January 2008 and January 2011. The diagnosis of varicocele was based on findings from both physical examination and color Doppler ultrasound. Varicocele grades were defined as grade I-palpable only with Valsalva, grade II-palpable without Valsalva, and grade III-visible from a distance [9]. Testicular volume was measured ultrasonographically using the formula: $0.71 \times$ length $\times$ width $\times$ height. Testicular hypotrophy was defined as $20 \%$ volume or greater differential between testicles [10].

Inclusion criteria included: patients who described pain with testicular discomfort as a dull ache, scrotal heaviness or throbbing
Table 2. Factors which may affect pain resolution

\begin{tabular}{lcll}
\hline Variable & Success & Failure & $\mathrm{p}$ \\
\hline High inguinal $(\mathrm{n}=37)$ & $32(86.5 \%)$ & $5(13.5 \%)$ & 0.526 \\
Subinguinal $(\mathrm{n}=93)$ & $84(90.3 \%)$ & $9(9.7 \%)$ & \\
Grade III $(\mathrm{n}=79)$ & $73(92.4 \%)$ & $6(7.6 \%)$ & 0.218 \\
Grade II $(\mathrm{n}=48)$ & $41(85.4 \%)$ & $7(14.6 \%)$ & \\
Grade I $(\mathrm{n}=3)$ & $2(66.6 \%)$ & $1(33.4)$ & \\
$>6$ months $(\mathrm{n}=89)$ & $83(93.3 \%)$ & $6(6.7 \%)$ & 0.012 \\
$<6$ months $(\mathrm{n}=41)$ & $32(78 \%)$ & $9(22 \%)$ & \\
Dull pain $(\mathrm{n}=86)$ & $79(91.9 \%)$ & $7(8.1 \%)$ & 0.766 \\
Throbbing pain $(\mathrm{n}=44)$ & $37(84 \%)$ & $7(16 \%)$ & \\
\hline
\end{tabular}

pain, especially after standing a long time. Varicocele was proved by Doppler, and after failed medical treatment, all our patients underwent a preoperative trial of conservative management for pain (non-steroidal anti-inflammatory medication, scrotal elevation and limitations of activity) for 4.6 weeks (range 2-8 weeks). Patients who had other causes of scrotal pain, such as testicular torsion, epididymitis, inguinal hernia, testicular tumor or trauma, were excluded from the study.

All data about the patients were prospectively reported in a preformed sheet including patient age, varicocele grade, varicocele laterality, duration and quality of pain, response to conservative therapy, pre- and post-operative semen parameters (3 parameters were used to assess semen parameters improvement: sperm count per $\mathrm{ml}$, percent normal morphology and percent fast linear motility 60 minutes after ejaculation) and surgical approach to ligation. According to the duration of pain before surgery the patients were divided into 2 groups. The first group consisted of 89 patients whose pain had existed longer than 6 months. The second group was composed of 41 patients who had a short duration of pain, less than 6 months.

The first follow-up visit was after 1 week to check the wound and then they were instructed to attend a second follow-up visit after 3 months but only 130 patients attended.

Follow-up evaluation included physical examination, questioning of pain severity (compared with preoperative pain severity), development of any postoperative complications, and color Doppler to study recurrence reflux. After surgery patient response was graded as a complete response (pain was completely absent after surgery), partial response (pain persisted but was reduced after surgery) and no response (pain remained unchanged after surgery) [11].

\section{Results}

From January 2008 to January 2011, 397 patients underwent varicocele ligation in our ward. Of these men, $252(63.6 \%)$ were operated for infertility, $105(26.4 \%)$ for pain, and $40(10 \%)$ complained of both pain and infertility, none of them showed preoperative testicular hy- 
Table 3. Comparison of studies of surgical treatment of painful varicocele

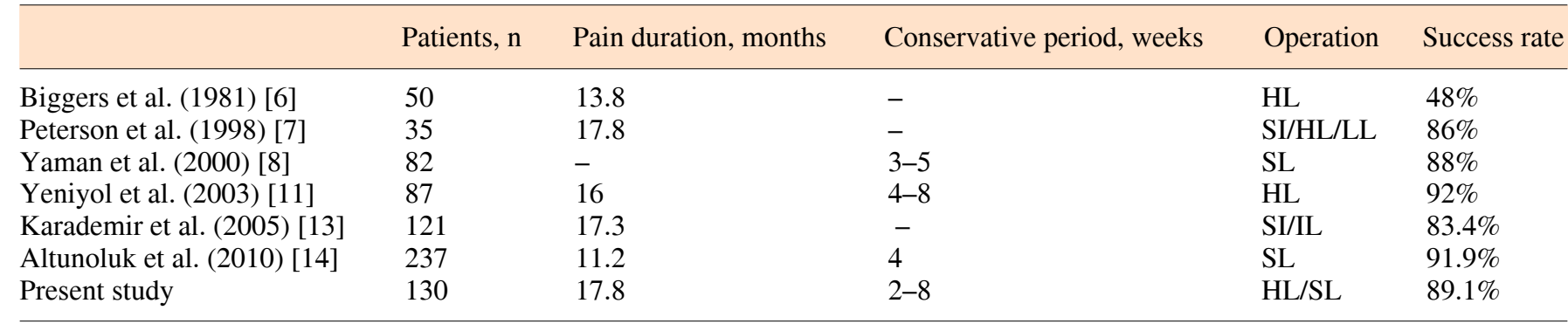

$\mathrm{HL}=$ High ligation; $\mathrm{IL}=$ inguinal ligation; $\mathrm{LL}=$ laparoscopic ligation; $\mathrm{SL}=$ subinguinal ligation.

potrophy, and preoperative testicular volumes were $16 \pm$ $3.7 \mathrm{ml}$. While waiting for surgery, 7 (4.6\%) patients decided not to undergo surgery because their pain resolved with conservative management. None of the patients in the study had testicular hypotrophy.

Of the 145 men operated on for pain, 130 (89.6\%) were available for follow-up. Average patient age at varicocele ligation for pain was 25.7 years (range 19-39 years). Average duration of pain before presentation to our clinic was 17.8 months (range 1-37 months) with 86 $(66 \%)$ patients describing the preoperative pain as dull and $44(34 \%)$ as a throbbing ache. Average follow-up after surgery was 10.9 months (range 5-36 months) (table $1)$.

The varicocele was on the left side in $118(90.8 \%)$ patients and bilateral in $12(9.2 \%)$, all of the patients complained of left side pain with grade III varicocele and a symptomatic right side grade I and they underwent unilateral left side varicocelectomy. Varicocele was grade III in $79(60.8 \%)$ cases, grade II in $48(36.9 \%)$ and grade I in $3(2.3 \%)$. No patients reported a history of epididymitis, sexually transmitted diseases, urinary tract infections or prostatitis.

A subinguinal approach was used in 93 patients (71.5\%), and high ligation in $37(28.5 \%)$ patients. There were no intraoperative complications. Postoperative complications consisted of 4 hydroceles, 3 wound infections treated with oral antibiotics and 1 hematoma. There was not any testicular atrophy and postoperative testicular volumes were $17.3 \pm 4.7 \mathrm{ml}$. There were no deaths reported as a complication in any of the procedures.

Of the 130 patients contacted after surgery, 109 $(83.8 \%)$ reported complete resolution of pain, 7 (5.4\%) had partial resolution of pain and 14 did not show benefit

Varicocelectomy for Painful Varicocele from surgery. Recurrence was detected in 1 of 14 patients who had persistent scrotal pain. While the success rate of the patients with a long period of pain was $83 / 89$ $(93.3 \%)$, patients who had short duration of pain had a success rate of 32/41 (78\%). Table 2 shows a comparison of treatment outcomes in terms of varicocele grade, quality and duration of pain, and operation techniques.

\section{Discussion}

Varicocelectomy is indicated in the case of infertility, or when associated with persistent pain [4]. Treatment for painful varicocele traditionally consists of conservative measures and surgery is only recommended where conservative management has failed and in a highly selected population of men who have specific pain complaints. Conservative efforts consist of scrotal support, anti-inflammatory medications and limitations of activity often leading to unacceptable lifestyle limitations.

We performed a total of 397 varicocele ligations in the period between 2008 and 2011, and 145 (36.4\%) were done for pain. This percentage of patients operated on for pain is less than other studies which is between 48 and $61 \%$ [6-8]. All patients were kept on 4.6 weeks (range 2-8 weeks) conservative treatment before decision of surgery. In the study period, 7 out of $152(4.6 \%)$ patients responded well to conservative treatment and did not undergo surgery, and the same result was reported by Yaman et al. [8], while Yeniyol et al. [12] found that in a few patients, temporary resolution of scrotal pain occurred but all underwent surgical treatment.

Peterson et al. [7] and Yaman et al. [8] reported complete resolution of pain in 86 and $88 \%$ of patients, re- 
spectively. Yeniyol et al. [12] showed that high ligation of varicocele is effective to treat pain with similar results $(82.8 \%)$. Our success rate $(89.2 \%)$ had a compatible level. On the contrary, Biggers et al. [6] reported a success rate of only $48 \%$. Table 3 shows the comparisons of studies on surgical treatment of painful varicocele.

We reported an average 17.8 months (range 1-37 months) period of pain before surgery, it was very different from studies in which the period was between 3 and144 months but the average time was 13.8-17.8 months for the patients to consult a doctor for scrotal pain [6-8]. Duration of pain before surgery could be a factor used to predict success where patients presenting with long-lasting pain had significant success in the resolution of pain. On the other hand, patients presenting with short period of pain significantly failed to benefit from varicocele ligation. Yeniyol et al. [12] stated that only the duration of pain seems to be a factor that considerably affects the pain resolution rate.

Authors stated that patients presenting with dull pain had more significant success in the resolution of pain than patients with sharp pain. It is thought that the postoperative success rate is associated with pain characteristics [13], but our study showed an insignificant relation between pain resolution and quality of pain. Peterson et al. [7] stated that the pain must be dull, aching and throbbing without components of sharp or radiating pain. All our patients' complaints fully matched these pain crite- ria. Also we did not find any significant relation between the type of varicocele ligation approach and the response to pain, the same as other studies [12]. However, Karademir et al. [14] showed a success rate of $83.4 \%$ using inguinal and subinguinal ligation and suggested that surgical technique may influence outcomes.

We confirm suggestion of Altunoluk et al. [15] that there is no association between varicocele grade and pain resolution after surgery. However, Yaman et al. [8] suggested that the failure rate was associated with the preoperative varicocele grade. In the present study recurrence using color Doppler ultrasound in the failure group was examined and reflux recurrence was found in 1 of the 14 patients who did not show a benefit from surgery. This result would suggest that persistence of pain was probably not related to varicocele recurrence, and this is compatible with other studies [12] and underlying pathology other than varicocele, such as idiopathic orchialgia, epididymitis, or a surgical complication (e.g., hydrocele) might be the cause of treatment failure after non-microsurgical varicocelectomy [16].

In conclusion, varicocelectomy is a successful option for treatment of painful varicocele in selected patients (who have specific complaints, an accurate diagnosis, and in whom conservative management has been tried and failed). There was no association between varicocele grade, quality of pain, type of varicocele ligation, or recurrence and pain resolution after surgery, and only duration of pain may predict outcomes in patients.

\section{References}

1 Schlesinger MH, Wilets IF, Nagler HM: Treatment outcome after varicocelectomy. A critical analysis. Urol Clin North Am 1994; 21:517-529.

2 Kass EJ, Marcol B: Results of varicocele surgery in adolescents: a comparison of techniques. J Urol 1992;148:694-696.

>3 Marmar JL, Kim Y: Subinguinal microsurgical varico $\neg$ celectomy: a technical critique and statistical analysis of semen and pregnancy data. J Urol 1994;152:1127-1132.

-4 Schwentner C, Oswald J, Lunacek A,Deibl M, Bartsch G, Radmayr C: Optimizing the outcome of microsurgical subinguinal varicocelectomy using isosulfan blue: a prospective randomized trial. J Urol 2006; 175:10491052.

5 Goldstein M: Varicocelectomy: general considerations; in Goldstein M (ed): Surgery of male infertility. Philadelphia, WB Saunders, 1995, p84.

\footnotetext{
Biggers RD, Soderdahl DW: The painful var- 12 Yeniyol CO, Tuna A, Yener H, Zeyrek N, icocele. Mil Med 1981;146:440-441.

$\checkmark 7$ Peterson AC, Lance RS, Ruiz HE: Outcomes of varicocele ligation done for pain. J Urol 1998;159:1565-1567.

-8 Yaman O, Ozdiler E, Anafarta K, Gogus O: Effect of microsurgical subinguinal varicocele ligation to treat pain. Urology 2000;55: 107-108.

-9 Lyon RP, Marshall S, Scott MP: Varicocele in childhood and adolescence: implication in adulthood infertility? Urology 1982;19: 641-644.

10 VanderBrink BA, Palmer LS, Gitlin J, Levitt SB, Franco I: Lymphatic-sparing laparoscopic varicocelectomy versus microscopic varicocelectomy: is there a difference? Urology 2007;70:1207-1210.

$>11$ Levine LA, Matkov TG, Lubenow TR: Microsurgical denervation of the spermatic

\begin{abstract}
Tilki A: High ligation to treat pain in varicocele. Int Urol Nephrol 2003;35:65-68. RA, Nathan S: Predictors of success in surgical ligation of painful varicocele. Urol Int 2007;79:33-36. Iseri C, Erden D: Evaluation of the role of varicocelectomy including external spermatic vein ligation in patients with scrotal pain. Int J Urol 2005;12:484-488. Duration of preoperative scrotal pain may predict the success of microsurgical varicocelectomy. Int Braz J Urol 2010;36:55-59. crosurgical varicocelectomy for recurrent or persistent varicoceles associated with orchalgia. Urology 2005;66:1072-1074.
\end{abstract}

13 Al-Buheissi SZ, Patel HR, Wazait HD, Miller

-14 Karademir K, Senkul T, Baykal K, Ates F,

15 Altunoluk B, Soylemez H, Efe E, Malkoc O:

$\checkmark 16$ Chawla A, Kulkarni G, Kamal K, Zini A: Mi-
} cord: a surgical alternative in the treatment of chronic orchialgia. J Urol 1996;155:10051007. 